\title{
Tribological performance and scuffing behaviors of several automobile piston rings mating with chrome-plated cylinder liner
}

\author{
Zeyu MA ${ }^{1}$, Ruoxuan HUANG ${ }^{1, *}$, Xiaoshuai YUAN ${ }^{2}$, Yan SHEN ${ }^{3}$, Jiujun $\mathrm{XU}^{4, *}$ \\ ${ }^{1}$ Department of Materials Science and Engineering, Dalian Maritime University, Dalian 116026, China \\ ${ }^{2}$ China North Engine Research Institute (Tianjin), Tianjin 300400, China \\ ${ }^{3}$ Marine Engineering College, Dalian Maritime University, Dalian 116026, China \\ ${ }^{4}$ Key Lab of Ship-Machinery Maintenance \& Manufacture, Dalian Maritime University, Dalian 116026, China \\ Received: 27 July 2020 / Revised: 15 October 2020 / Accepted: 24 May 2021 \\ (C) The author(s) 2021.
}

\begin{abstract}
The friction and wear properties, as well as the scuffing resistance, of different piston-ring coatings mating with a chrome-plated cylinder liner were investigated. Interrupted wear tests under the lubricant starvation condition were conducted to examine the wear behavior of Cr-diamond coating (GDC) and diamond-like coating (DLC). The results indicated that the DLC coating had outstanding tribological properties (small coefficient of friction and wear loss) at $150{ }^{\circ} \mathrm{C}$, while the GDC coating exhibited better performance at an elevated temperature $\left(240^{\circ} \mathrm{C}\right)$. The DLC coating had a better scuffing resistance; no material adhesion occurred for $70 \mathrm{~min}$ under the unlubricated condition. The interrupted wear behaviors revealed that the scuffing process of the GDC coating involved the consumption of lubricant oil with relatively stable wear, a reduction in the friction force, and the occurrence of scuffing, in sequence. In contrast, although the friction force also increased after a short period of weak friction, no scuffing was observed. This is attributed to the formation of a mixed oxide and graphitic $\mathrm{C}$ tribolayer.
\end{abstract}

Keywords: chrome-plated; cylinder liner; piston ring; scuffing; Cr-diamond coating (GDC); diamond-like coating (DLC)

\section{Introduction}

The output power of engines has been continuously increasing, necessitating various technical developments. The technology for improving engine efficiency can be roughly divided into the following categories: newconcept combustion technology, variable mechanism, electronic control and ultraprecision, and reduced friction loss [1]. Reducing the frictional power consumption of the engine places even more stringent requirements on the moving parts inside the engine. The piston ring pack-cylinder liner is one of the most essential components owing to the high friction power loss $[2,3]$. The dead center position of the piston ring and cylinder liner is generally under mixed lubrication and boundary lubrication conditions because of the high temperature and high load, aggravating the wear of the friction pair. The wear condition of the two determines the reliability and durability of the whole machine [4-6]. A more severe type of accident occurs between the piston ring and the cylinder liner is scuffing, which is described as a more complex catastrophic accident [7]. Therefore, it is necessary to better understand the wear and scuffing performance, as well as the associated behaviors, of the piston ring and cylinder liner friction pair.

* Corresponding authors: Ruoxuan HUANG, E-mail: huan0237@e.ntu.edu.sg; Jiujun XU, E-mail: xu.jiujun@163.com 
The development of piston rings with excellent performance has always presented a challenge for the piston-ring manufacturing industry. There are many techniques for improving the performance of the piston ring, e.g., surface treatment is effective and commonly used. Numerous engineering coatings have been developed to enhance the friction and wear properties of the piston ring under severe operating conditions and prevent scratches [8-11]. The nitriding process has various advantages for piston rings, e.g., the wear amount and specific wear rate are reduced [12]. Additionally, a PVD-CrN coating can be deposited via cathodic arc technology. This coating has good toughness, abrasion resistance, and tensile properties. As an enhanced version of the chrome ceramic coating, Cr-diamond coating (GDC), which comprises a $\mathrm{Cr}$ matrix and reinforced microdiamond particles embedded in an ultrafine cracked mesh, exhibits excellent wear resistance. Diamond-like coating (DLC) has an extremely high hardness (as hard as $90 \mathrm{GPa}$ ) and elasticity, as well as a small coefficient of friction [10]. When the $\mathrm{C}$ atoms are entirely formed into pure stone ink crystals via $\mathrm{sp}^{2}$ bond formation, pure $\mathrm{sp}^{3}$ bonds are combined to form pure diamonds. The DLC film, consisting of both $\mathrm{sp}^{2}$-bonded form and $\mathrm{sp}^{3}$-bonded form, presents the combined characteristics of diamond and graphite. Piston rings with different coatings exhibit different tribological performance when mating with the cylinder. Thus, identifying the best candidate is essential for the optimization of the engine piston group.

Numerous studies have been conducted on the friction and wear properties of the aforementioned engineering coatings. Liu et al. [13] deposited the graphite-like C (GLC) coating and two types of DLC coatings on a GCr15 substrate and investigated their tribological properties. However, the experimental conditions differed significantly from the actual working situation, e.g., the low temperatures (only 25 and $90{ }^{\circ} \mathrm{C}$ ). Wan et al. [14] examined the wear mechanism of hard amorphous GLC in combination with conventional ceramic coatings. However, no explanation for why the friction force was reduced before scuffing was presented in their work. Scuffingone of the most challenging questions in tribology - is not well understood. Considerable effort has been directed toward explaining the scuffing mechanisms from different aspects. It has been documented that the accumulation of wear debris and the oil-film rupture are two factors that can eventually lead to scuffing [15]. The formation of the oxide film is beneficial for delaying the wear process, when the oxide film is reduced and removed, scuffing occurs [16]. All of these are related to the friction surface protection layer of the friction pair. Hershberger et al. [17] found that scuffing was caused by adiabatic shear instability, and occurred when the local thermal softening rate exceeded the work-hardening rate. Ajayi et al. [7] reported that the expansion of scuffing would be delayed if the local heat generated during the scuffing process could be quickly dissipated; otherwise, the scuffing would spread, resulting in a catastrophic failure. It was also reported that austenite was formed during wear, which was inseparable from local heating [18]. These theories were analyzed at the microscale. In contrast, Markov and Kelly [19] believed that the degree of plastic deformation at the microscale affected the development of scuffing and that scuffing had nothing to do with the macroscopic mechanical properties. Piekoszewski et al. [20] believed that the rheological properties of the lubricant (characterized by the kinematic viscosity and viscosity index) did not affect the scuffing process.

In many studies, observations of the worn surface were used to investigate the scuffing process. Yagi et al. [21] used a new system comprising two-dimensional detector synchronous X-ray diffraction and a nearinfrared charge-coupled device (CCD) array as well as a visible-light CCD array to observe the scuffing process. They divided the scuffing process into microscuffing, normal wear, micro-scuffing, and macroscuffing stages. Studies performed by Matsuzaki et al. [22] revealed that the plastic flow occurred immediately after the transfer layer passed through the contact zone. Each instance of plastic flow lasted for a few milliseconds. The speed of the plastic flow was significantly lower than the sliding speed. At the end of the fast-plastic flow process, the brightness of the area of the plastic flow increased, which was attributed to the oxidation of the steel surface. These observations of the scuffing process focused on the plastic flow; few were related to the frictional changes with the scuffing process.

The present study focused on the wear behaviors 
of four typical piston-ring coatings mating with a Cr-plated cylinder liner. The associated scuffing process was analyzed on the basis of the changes in the surface morphology and chemical state. Additionally, the friction and wear properties of the different coatings were evaluated via wear tests and stepwise loading tests.

\section{Experimental}

\subsection{Materials and lubricants}

A $45^{\circ}$ honed platform Cr-plated cylinder liner with inner and outer diameters of 110 and $126 \mathrm{~mm}$, respectively, was used in this study. The cylinder-liner specimens were cut equally from the liner along the circumferential direction by $9^{\circ}$. The dimensions of the cut liner specimens were $43 \mathrm{~mm} \times 8.6 \mathrm{~mm} \times 8 \mathrm{~mm}$. The piston ring was carefully machined into 30 equal parts with a central angle of $12^{\circ}$. Both the liner and ring specimens were cut via electrical discharge machining.

Four types of commercial piston rings with different engineered coatings (nitriding, PVD-CrN, GDC, and DLC) were selected as the counterpart materials. The cross-sectional morphologies of the four coatings with the substrate are shown in Fig. 1. The thicknesses of the PVD-CrN and DLC coatings were approximately $15 \mu \mathrm{m}$; they were far thinner than the nitriding and GDC coatings. The PVD-CrN coating was relatively dense, and the DLC coating had hole defects, possibly because of the hydrogen evolution reaction during the

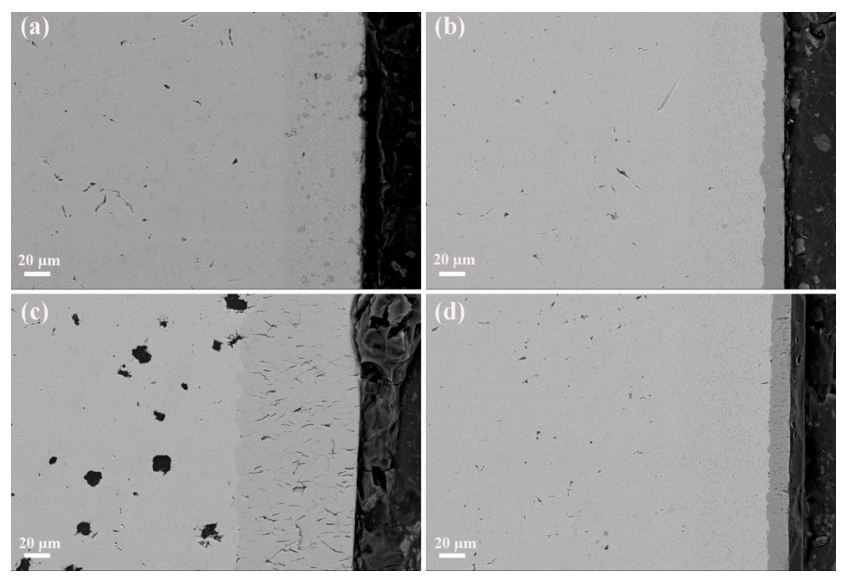

Fig. 1 Cross-sectional scanning electron microscopy (SEM) images of the piston-ring coatings: (a) nitriding; (b) PVD-CrN; (c) GDC; (d) DLC. preparation process [10]. Many cracks were observed in the GDC coating. The microhardness and surfaceroughness values of the liner and piston-ring specimens are presented in Table 1.

RP-4652D (5W-40CF-4) diesel oil, which is commercially available from Beijing Xingpu Fine Chemical Technology Development Co., Ltd., China, was used as the lubricant. The evaporation loss of this oil is $5.58 \% / \mathrm{h}$ at $250{ }^{\circ} \mathrm{C}$. The kinematic viscosity of this oil is $14.99 \mathrm{cSt}$ at $100^{\circ} \mathrm{C}$.

\subsection{Wear and friction tests}

A contraposition reciprocating test rig developed in-house was utilized to evaluate the wear resistances of different coated rings under the lubricant condition (Fig. 2(a)). The arrangement of the piston ring and the cylinder liner in this tribo-system is shown in Fig. 1(b). The piezoelectric sensor-controlled load is perpendicularly applied to the friction pair surface, and the friction force is measured in real time by a horizontal sensor (the normal load can reach $380 \mathrm{MPa}$ ). The machine can provide a $30 \mathrm{~mm}$ reciprocating stroke. The reciprocating speed can be adjusted between 0.01 and $1 \mathrm{~m} / \mathrm{s}$, and the temperature ranges from 30 to $300{ }^{\circ} \mathrm{C}$ [23].

The friction properties of the coatings sliding against the liner were evaluated via a $24 \mathrm{~h}$ wear test. The parameters of the experiment are presented in Table 2. The coefficient of friction was calculated using the ratio of the friction force to the normal load in the stable period ( $24 \mathrm{~h}$ test: the average of the last 1,000 cycles). Before each test, the specimens were ultrasonically cleaned in an alcohol solution for $10 \mathrm{~min}$ to remove surface impurities. After the test, the

Table 1 Microhardness and surface-roughness values of the liner and coated ring specimens.

\begin{tabular}{cc}
\hline Material & Property \\
\hline & Nitriding, hardness: $1,109.5 \mathrm{HV}_{0.2}, R a=0.41 \mu \mathrm{m}$ \\
Rings & PVD-CrN, hardness: $1,400.0 \mathrm{HV}_{0.2}, R a=0.26 \mu \mathrm{m}$ \\
& GDC, hardness: $839.1 \mathrm{HV}_{0.2}, R a=0.21 \mu \mathrm{m}$ \\
& DLC, hardness: 2755.6 $\mathrm{HV}_{0.2}, R a=0.28 \mu \mathrm{m}$ \\
\hline $\begin{array}{c}\text { Cylinder } \\
\text { liner }\end{array}$ & Plating: pure chrome \\
& Matrix: AISI $5120 \mathrm{steel}$ \\
& Dimensions: $43 \mathrm{~mm} \times 8.6 \mathrm{~mm} \times 8 \mathrm{~mm}$ \\
\hline
\end{tabular}




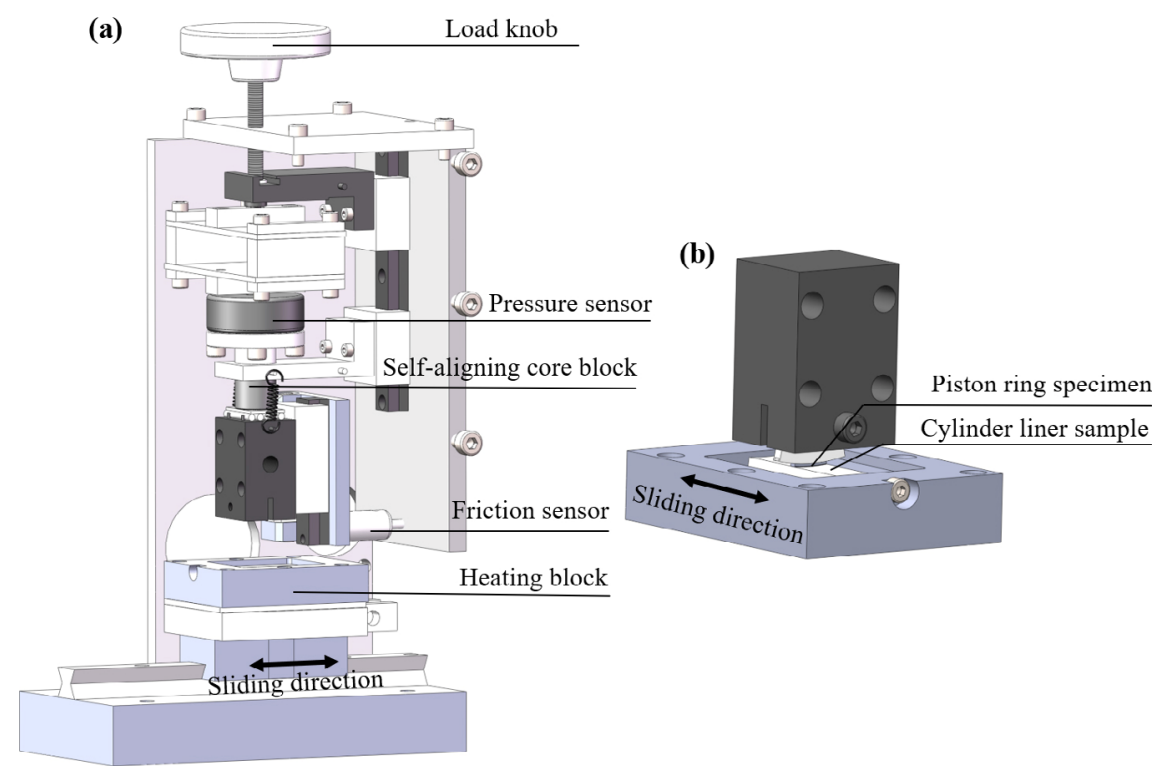

Fig. 2 Contraposition reciprocating test rig.

Table 2 Parameters of the $24 \mathrm{~h}$ wear test.

\begin{tabular}{cc}
\hline Stage & Parameters \\
\hline Running-in & $0.4 \mathrm{~m} / \mathrm{s}, 150{ }^{\circ} \mathrm{C} / 240{ }^{\circ} \mathrm{C}, 10 \mathrm{MPa}, 3 \mathrm{~h}$ \\
Experiment & $0.4 \mathrm{~m} / \mathrm{s}, 150{ }^{\circ} \mathrm{C} / 240{ }^{\circ} \mathrm{C}, 80 \mathrm{MPa}, 21 \mathrm{~h}$ \\
\hline
\end{tabular}

specimens were soaked in acetone for another $10 \mathrm{~min}$ to remove excess oil on the surface. A speed of $0.4 \mathrm{~m} / \mathrm{s}$ was maintained throughout the tests. The lubricant oil was continuously supplied by a peristaltic pump at a rate of $0.1 \mathrm{~mL} / \mathrm{min}$. A dose of oil was injected into the contact area by a syringe before each run. The friction force and sliding time were recorded automatically during the test. Each type of friction pair was tested four times.

\subsection{Scuffing tests}

The severe wear of the friction pair of the piston ring and the cylinder liner mainly occurs at the top dead center (TDC) and bottom dead center positionsparticularly the TDC-because of the low sliding velocity and high temperature. The TDC is prone to the initiation of scuffing. The boundary lubrication of the TDC can be simulated using the developed test rig with the parameters presented in Table 3 [24]. In the scuffing tests, the piston ring/cylinder liner was initially subjected to a running-in process with two periods before the lubricating oil supply was cut off. Subsequently, the piston ring/cylinder liner continued
Table 3 Parameters of the scuffing test.

\begin{tabular}{ccccc}
\hline Period & $\begin{array}{c}\text { Temperature } \\
\left({ }^{\circ} \mathrm{C}\right)\end{array}$ & $\begin{array}{c}\text { Load } \\
(\mathrm{MPa})\end{array}$ & $\begin{array}{c}\text { Time } \\
(\mathrm{min})\end{array}$ & $\begin{array}{c}\text { Speed } \\
\left(\mathrm{m} \cdot \mathrm{s}^{-1}\right)\end{array}$ \\
\hline Low-load period & 120 & 10 & 10 & 0.4 \\
High-load period & 240 & 40 & 150 & 0.4 \\
Fuel-cutoff period & 240 & 40 & Until scuffing & 0.4 \\
\hline
\end{tabular}

to run for some time under the oil-starved condition until scuffing occurred. The typical phenomenon observed was a sudden increase in friction accompanied by harsh noise. The time interval between the oil cutoff and scuffing was recorded to investigate the antiscuffing properties of the friction pairs. Each type of friction pair was tested four times.

To investigate the scuffing process associated with the friction and wear behaviors after the oil cutoff, interrupted tests were conducted as well. According to the variation of the friction force, four different points after the oil cutoff were selected: 1 ) the end of the high running-in load, 2) 5 min after the oil cutoff, 3) the moment of the friction reduction, and 4) the moment of severe scuffing. In the oil-break tests, the two friction pairs were repeatedly tested three times at different time points.

\subsection{Characterization}

A ZEISS-SUPRA 55 SAPPHIRE scanning electron microscope (Oberkochen, Germany) and an energy- 
dispersive X-ray spectrometer (EDS, Oxford Instruments, UK) were utilized to examine the morphology and chemical composition of the wear area of the piston ring/cylinder liner. The roughness $R a$ of the piston ring/cylinder liner was measured by using a Hommel Tester T6000 surface profiler (Hommel, Germany) and a confocal laser scanning microscope (Olympus LEXT OLS4000, Tokyo, Japan). In the wear and friction tests, the wear steps of the worn and unworn areas of the piston ring/cylinder liner were measured via confocal laser scanning microscopy. The X-ray photoelectron spectroscope (XPS, Thermo Fisher Scientific ESCALAB 250Xi, Massachusetts, USA) was used to analyze the chemical products on the surface of the friction pair. The test parameters were as follows: a full-spectrum energy of $100 \mathrm{eV}$ (step length of $1.0 \mathrm{eV}$ ) and a narrow-spectrum energy of $30 \mathrm{eV}$ (step length of $0.05 \mathrm{eV}$ ). The analysis room was under vacuum conditions, with a pressure of $<2.7 \times 10^{7} \mathrm{mBar}$. The results were calibrated repeatedly with the $C 1$ s peak $(284.8 \mathrm{eV})$.

\section{Results}

\subsection{Friction properties of four coatings mating with Cr liner}

Figure 3 shows the variation of the friction forces of different friction pairs at 150 and $240{ }^{\circ} \mathrm{C}$. At the lower temperature, the friction force of the DLC coating achieved stable wear in a shorter time. The DLC coating had a significantly weaker friction force than the other three coatings, as shown in Fig. 3(a). This is attributed to the co-existing $\mathrm{sp}^{2}$ and $\mathrm{sp}^{3}$ bond structures, which are beneficial for friction reduction. Nitriding exhibited the strongest friction force in the stable wear stage, followed by GDC and PVD-CrN.
As shown in Fig. $3(\mathrm{~b})\left(240{ }^{\circ} \mathrm{C}\right)$, DLC exhibited the weakest friction immediately after the load increased. After approximately $1 \mathrm{~h}$ of sliding, the friction force increased significantly, indicating scuffing. The scuffing occurred mainly because of the excessive internal stress accumulation of the DLC coating at the high temperature, which caused flake detachment. This agrees well with previous results indicating that DLC coatings are temperature-sensitive and that high temperatures degrade the tribological properties of the DLC coating [25]. The GDC exhibited the weakest friction throughout the high-load sliding period, owing to the high load-bearing capacity and self-lubrication of the diamond particles embedded in the coating during the wear process. The friction curve of PVD-CrN was smoother in the later stage of wear. The nitriding ring exhibited the strongest friction and poor friction stability under the high load, likely owing to its high roughness. As shown in Fig. 4 , at $150{ }^{\circ} \mathrm{C}$, the DLC ring exhibited the smallest coefficient of friction (0.106), followed by the GDC, PVD-CrN, and nitriding rings (0.113, 0.124, and 0.125, respectively). At $240{ }^{\circ} \mathrm{C}$, the GDC ring exhibited the smallest coefficient of friction (0.105), and the coefficients of friction of the PVD-CrN and nitriding rings were 0.128 and 0.157 , respectively.

\subsection{Wear of friction pairs at low and high tem- peratures}

Figure 5 shows the wear depths of the four pairs at 150 and $240{ }^{\circ} \mathrm{C}$. At $150{ }^{\circ} \mathrm{C}$, as shown in Fig. 5(a), the wear losses of both the ring and the cylinder liner were smaller for the DLC friction pair than for the other three friction pairs, owing to the coexistence of the graphite and diamond structures, which was beneficial for the wear resistance. The wear loss of the GDC friction pair was smaller than those of the nitriding
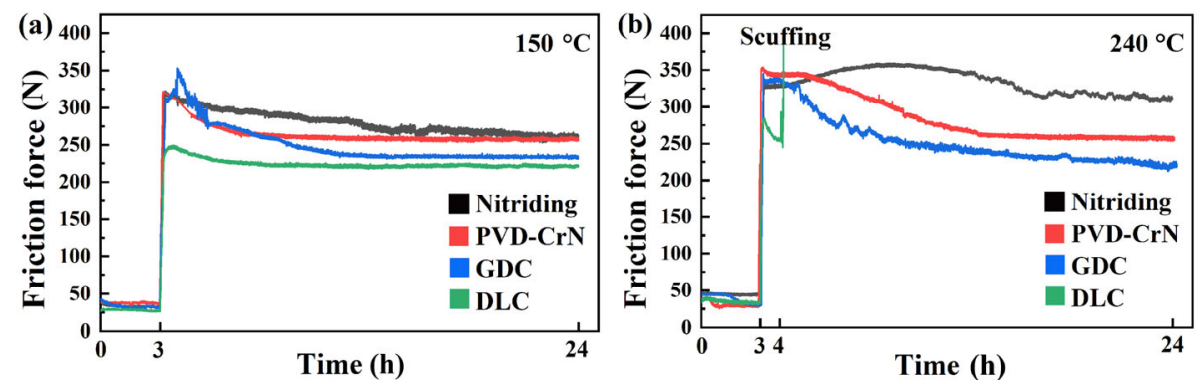

Fig. 3 Variation of friction forces with respect to the sliding time in the $24 \mathrm{~h}$ wear test: (a) $150{ }^{\circ} \mathrm{C}$; (b) $240{ }^{\circ} \mathrm{C}$. 


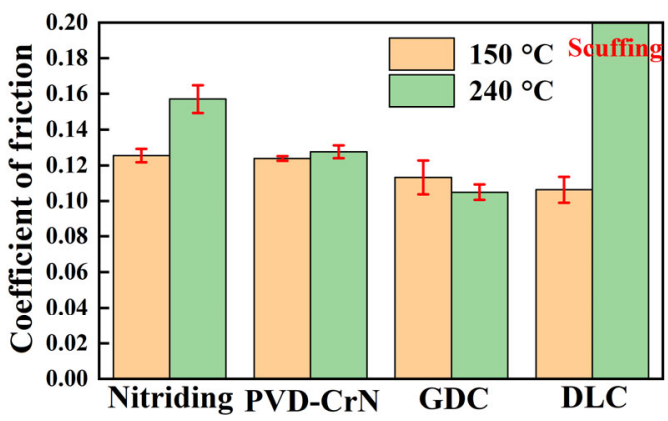

Fig. 4 Coefficients of friction of the $\mathrm{Cr}$ cylinder-liner specimen mating with different piston coatings at 150 and $240{ }^{\circ} \mathrm{C}$.
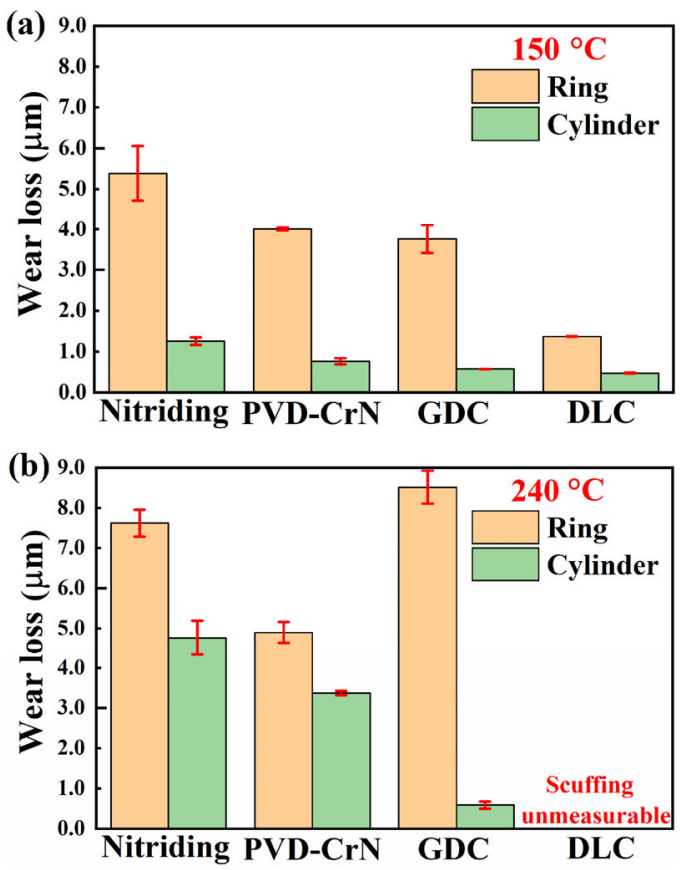

Fig. 5 Wear losses of the $\mathrm{Cr}$ cylinder liner and different ring specimens after the wear test: (a) $150{ }^{\circ} \mathrm{C}$; (b) $240{ }^{\circ} \mathrm{C}$.

and PVD-CrN friction pairs, possibly because of the lower roughness of the GDC piston ring. As shown in Fig. 5(b), the wear losses of the four friction pairs were larger at $240{ }^{\circ} \mathrm{C}$ than at $150{ }^{\circ} \mathrm{C}$. At $240{ }^{\circ} \mathrm{C}$, the scuffing of the DLC friction pair occurred; thus, the wear losses of the pairs could hardly be measured. According to the total wear loss of the piston ring and cylinder liner, the PVD-CrN friction pair was the best. The GDC piston ring resulted in the smallest wear loss of the cylinder liner, but the wear loss of the GDC coating was large. This is because the main element for both the liner and the ring was $\mathrm{Cr}$, and the Cr-GDC affinity was high; thus, adhesive wear was likely to occur. For the nitriding pair, both the coating and the liner exhibited large wear losses. In practical applications, the piston ring can be replaced during maintenance, but the cylinder liner should be kept unchanged throughout the lifecycle. Hence, if the protection of the liner is the key design factor, the GDC coating may be a suitable candidate. Practical conditions are far less harsh than $240{ }^{\circ} \mathrm{C}$ and $80 \mathrm{MPa}$; thus, the DLC coating will not be scuffed or peeled off and is considered a good choice.

\subsection{Friction characteristics of friction pairs in scuffing test}

Figure 6(a) shows the friction-force curves of the four pairs used in the scuffing tests. Each curve consists of three periods (low running-in load, high running-in load, and oil cutoff). After the two running-in periods, all the curves are stable, implying the good fitting of each friction pair. Subsequently, the friction of the DLC pair increased after the oil cutoff, whereas those of the nitriding, PVD-CrN, and GDC pairs exhibited the opposite trend. At the late stage of the oil cutoff, the DLC pair exhibited an increase and severe fluctuations in the friction force; in contrast, for the other three pairs, a short reduction followed by a significant increase in the curve was observed. The

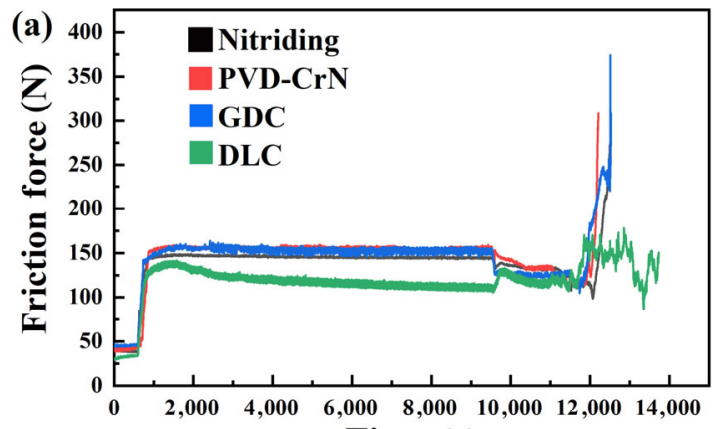

Time (s)

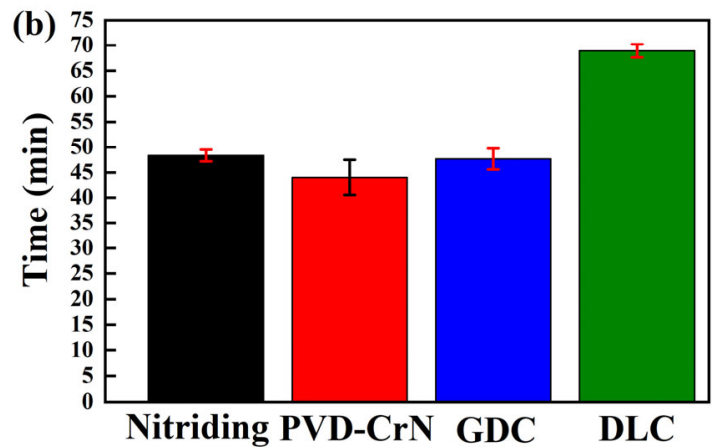

Fig. 6 Results of the scuffing tests: (a) variations of friction forces with respect to the sliding time; (b) anti-scuffing times of the different ring/cylinder pairs. 
instantaneous reduction of the friction force was likely caused by the reduced roughness of the cylinder-liner surface before the scuffing.

Figure 6(b) shows the time interval between the oil cutoff and the scuffing for the four pairs. The GDC and nitriding had nearly identical scuffing resistance abilities and slightly outperformed PVD-CrN. For the DLC pair, the wear process was similar to those of the other three types of mating pairs after the oil was cut off. The friction force changed at the beginning of the oil cutoff and then suddenly increased at approximately $40 \mathrm{~min}$. However, the differences were that the maximum friction force was $<200 \mathrm{~N}$ and there was no strong noise. This phenomenon sustains for another $30 \mathrm{~min}$, which can be longer if the test is not stopped. Moreover, the surfaces of the DLC and the cylinder liner were not significantly scratched after the test (Fig. 7(b), D4); thus, the slight scratching is the wear behavior of DLC when the lubrication oil is exhausted.

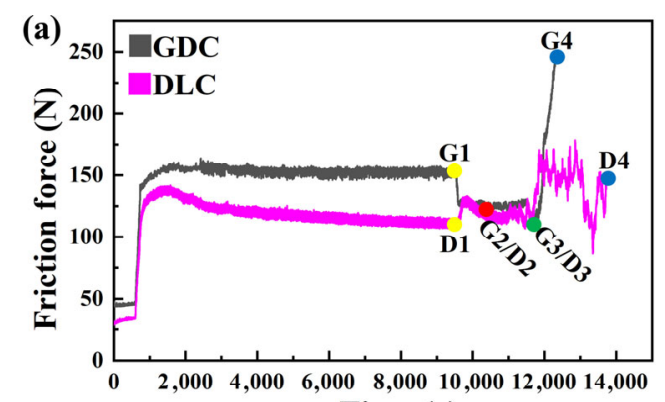

Time (s)

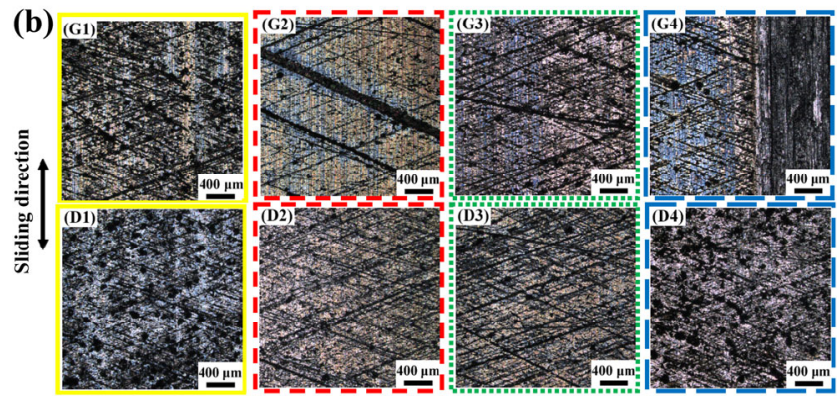

Fig. 7 Morphologies of the cylinder liner mating with GDC (G1-G4) and DLC (D1-G4) rings at different stages during the interrupted scuffing tests.

\section{Discussion}

\subsection{Wear behaviors under unlubricated condition}

The nitriding ring is not commonly used in engineering applications. At present, the PVD-CrN ring is predominantly used. The GDC and DLC rings may be suitable alternatives owing to their superior properties, which were observed in this study. As shown in Fig. 6, the friction force in the second stage exhibited two trends: rising and falling. Thus, the two typical coatings with the best performance (GDC and DLC) were selected for a further interrupted scuffing test. The interrupted points indicating the four stages and the corresponding cylinder-liner surface morphologies are shown in Fig. 7 (G: GDC/Cr liner friction pair; D: $\mathrm{DLC} / \mathrm{Cr}$ liner friction pair).

As shown in Fig. 7(b), from G1 to G4, the honing patterns on the surface of the liner were not entirely removed. For G3, there was a blue tribochemical film on the left side of the cylinder liner; in contrast, no film was observed on the right side. With the progress of the wear, the right side of the cylinder-liner surface was severely scratched at the stage of G4, while the left side was almost undamaged, likely owing to the protection provided by the blue tribofilm. The surface of the liner mating with DLC was subjected to the polishing and scuffing process in sequence as well, similar to the case of GDC, but the wear on the liner surface at the D4 stage was not as severe as that observed in G4. The surface-roughness values of the cylinder liners mating with GDC and DLC at different stages are presented in Fig. 8. As shown from Fig. 8, the roughness $(R a)$ decreased from stage 1 to stage 3 and then increased owing to the occurrence of slight scuffing. The roughness was the lowest at stage3, implying that the cylinder-liner surface was smooth at this moment, which is consistent with the friction reduction of stage3 in Fig. 7(a).

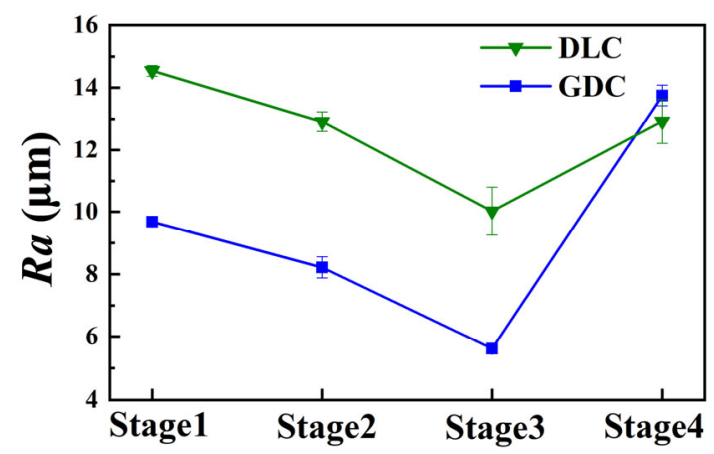

Fig. 8 Roughnesses of the cylinder liner mating with GDC and DLC at different interrupted points. 


\subsection{Scuffing mechanism of GDC and DLC mating with $\mathrm{Cr}$ liner}

As shown in Fig. 9, in the G1 stage, immediately after the oil cutoff, there were numerous fan-shaped dents on the surface of the chrome-plated cylinder liner, and the honed platform was continuously polished. At this time, the amount of friction reaction film on the platform was large, and the mass fraction of $\mathrm{Zn}$ was $13.55 \%$ (Fig. 9(b), G1). Additionally, a large amount of $\mathrm{Zn}$ compounds was distributed on the piston ring (Fig. 10(b), G1). Five minutes after the oil cut off, after the continuous grinding and polishing of the cylinder liner in the G2 stage, more scratches on the platform were observed, and they expanded, producing wear debris. Some of the wear debris was trapped in the pit; meanwhile, the pits can be expanded owing to the three-body abrasion. The others were removed from the friction pair. The mass fraction of $\mathrm{Zn}$ on the surface of the cylinder liner decreased to $7.67 \%$ (Fig. 9(b), G2), indicating that the tribofilm on the piston ring also decreased (Fig. 10(b), G2). When the friction force suddenly decreased after a plateau region-in the G3 stage-the $\mathrm{Zn}$ and $\mathrm{O}$ disappeared from the surface of the cylinder liner, implying that the tribofilm on the surface of the cylinder liner was almost consumed. Additionally, extensive microcracks identified as fatigue cracks appeared on the surface, reducing the strength of the cylinder-liner surface. There were also large fatigue cracks on the surface of the piston ring, and the sizes of the surface scratches were reduced after continuous polishing (Fig. 10(a), G3). In the G4 stage, the adhesive wear originated with the propagation of contact fatigue cracks and the wear of the tribofilm, inducing a noticeable plastic rheology along the sliding direction of the cylinderliner surface, and a large amount of material was peeled off (Fig. 9(a), G4). At this moment, the piston ring was covered with cylinder-liner material, because the piston ring was significantly harder than the cylinder liner. Additionally, the appearance of $\mathrm{O}_{2}$ on the surface of the cylinder liner (Fig. 9(b), G4) may have been due to the release of a large amount of heat when the piston ring and the cylinder liner were severely adhered, causing $\mathrm{Cr}$ to react with $\mathrm{O}$ in the air to form an oxide. When the GDC piston ring is paired with a chrome-plated cylinder liner, the thickness of
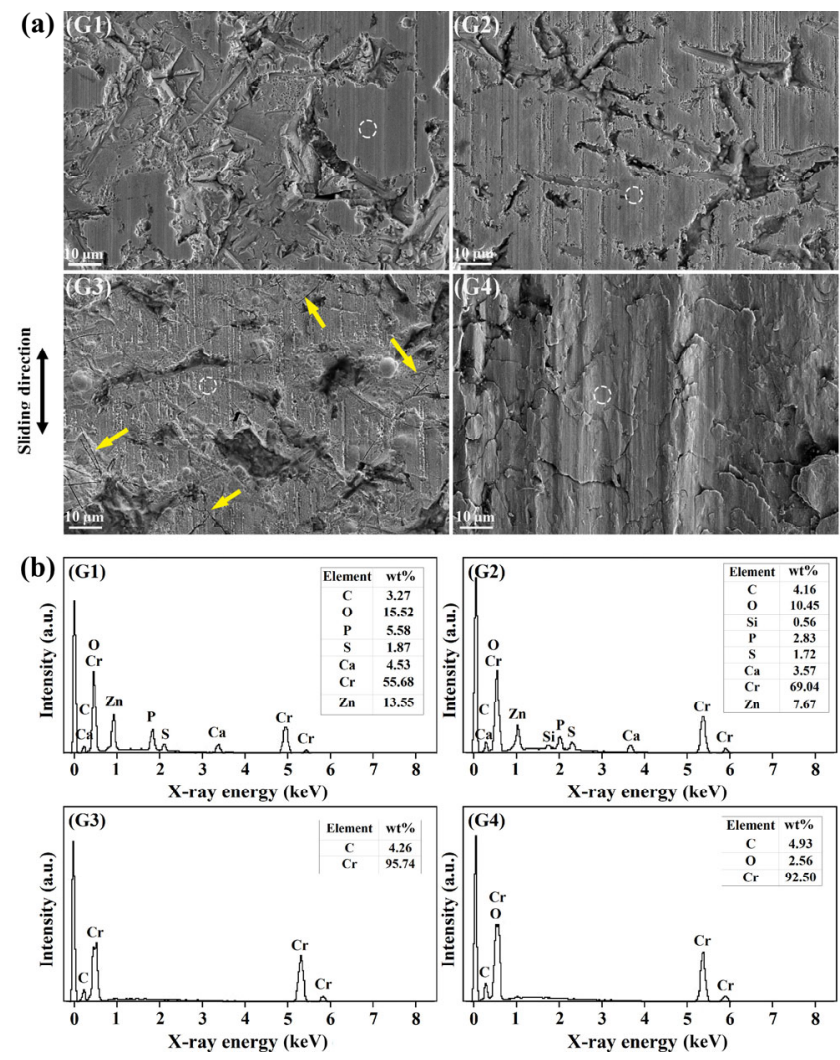

Fig. 9 Typical SEM images and EDS spectra of the cylinderliner specimen wear against the GDC ring at different interrupted points.
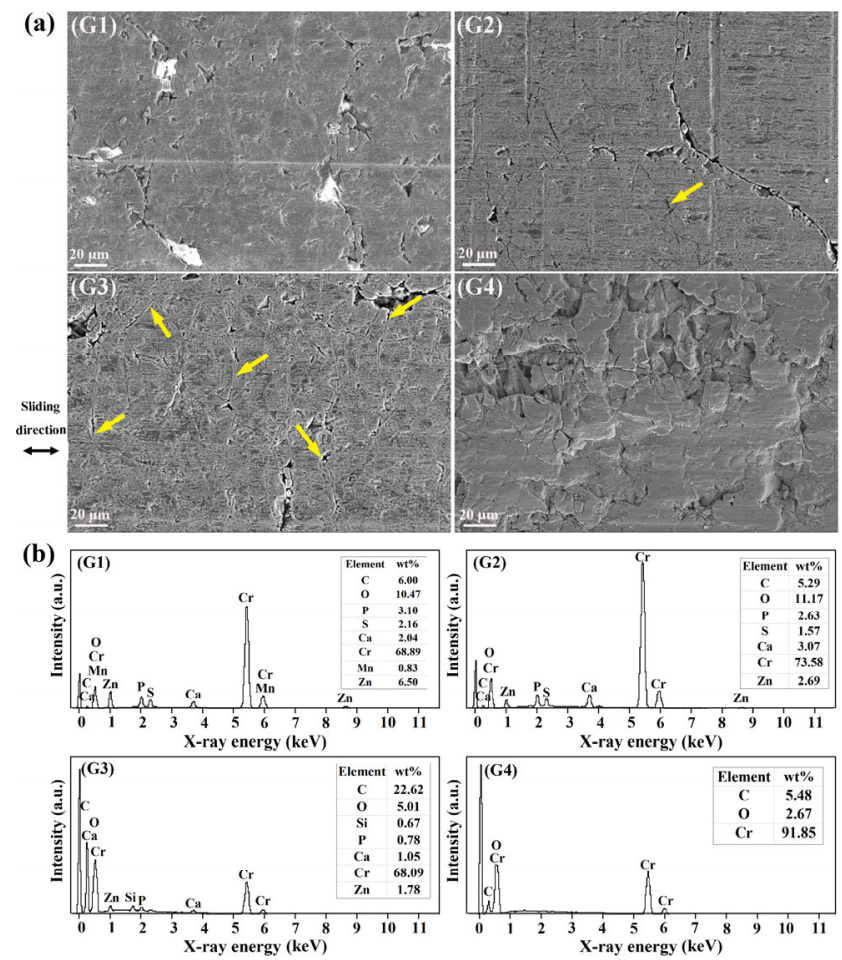

Fig. 10 Typical SEM images and EDS spectra of the GDC ring at different interrupted points. 
the chemical friction film decreases continuously over time after the oil supply is stopped, and scuffing occurs when the oil film eventually disappears [26].

When the chrome-plated cylinder liner mated with DLC, the surface was rough at the time of oil cutoff (Fig. 11(a), D1), exhibiting many small plateaus with clear honing patterns and pits. There were more ZDDP decomposition products on the surface, and the $\mathrm{Zn}$ content was $5.06 \%$ (Fig. 11(b), D1). There were more white bright substances (considered to be ZDDP decomposition products) on the surface of the piston ring (Fig. 12(a), D1 and D2). Then, the surface of the cylinder liner was polished to form a flat bearing platform. The $\mathrm{Zn}$ content was reduced to $2.99 \%$ (Fig. 11(b), D2). There were minor scratches on the surface of the piston ring, and the number of bright white spots was reduced (Fig. 12(a), D2). When the friction force decreased suddenly, the friction film on the surface of the cylinder liner decreased (Fig. 11(b), D3), and the $\mathrm{Zn}$ content decreased to $2.78 \%$. There were no fatigue cracks on the surface of the cylinder liner, in contrast to the case of GDC. Black shadows appeared on the surface. Meanwhile, the surface of the piston ring was polished and became smooth. From D1 to D3, the surface of the cylinder liner was slightly worn. When the friction continued to increase, numerous scratches appeared on the surface of the cylinder liner along the sliding direction, but the honing marks were still not completely removed. Under the action of strong friction, the surface of the cylinder liner was severely damaged compared with the previous stages (Fig. 11(a), D4), and there were numerous scratches on the surface of the piston ring (Fig. 12(a), D4). The amount of Zn compounds on the surface was reduced, but these compounds were not eliminated entirely, and more $C$ appeared (Fig. 11(b), D4). As shown in Fig. 13(a), the fluorescence spectrum of $C$ in the shadow of the cylinder liner was more prominent. Additionally, the energy spectrum labeled in Fig. 11(a), D4 is shown in Fig. 13(b). Large amounts of $\mathrm{C}$ and $\mathrm{O}$ appear, indicating that the dark shadow of D4 may have been caused by $\mathrm{C}$ deposition. These $\mathrm{C}$ atoms were mixed with other friction chemicals to form another special friction chemistry layer, which can suppress the occurrence of cylinder accidents when the oil film is degraded. As indicated by the XPS analysis results in Fig. 12(b), there was no $\mathrm{Cr}$ on
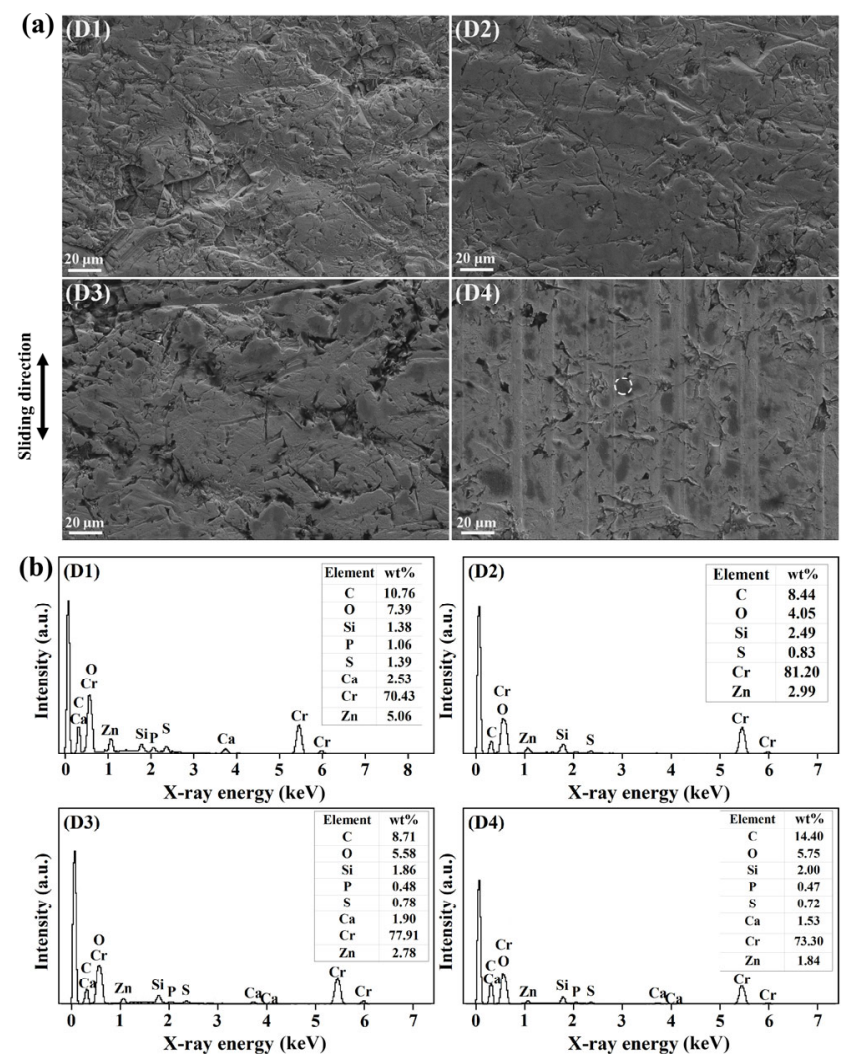

Fig. 11 Typical SEM images and EDS spectra of the cylinderliner specimen wear against the DLC ring at different interrupted points.

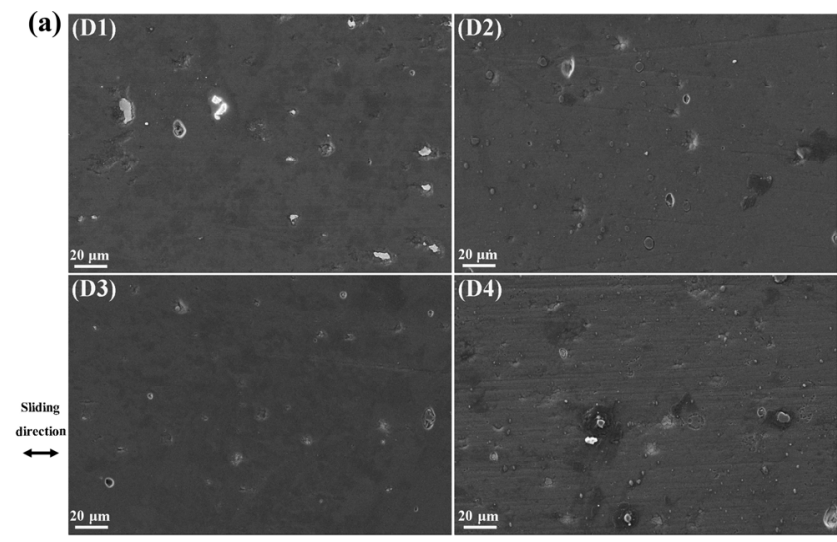

(b) $\mathrm{D}$

$\operatorname{Cr} 2 p$

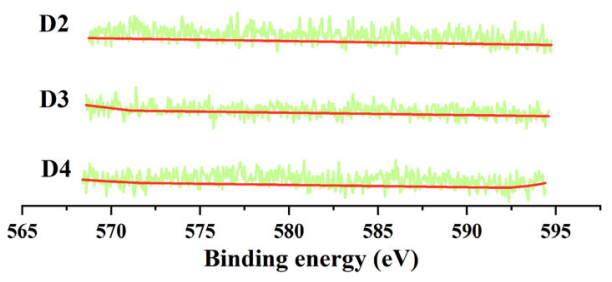

Fig. 12 (a) SEM images of the wear morphology of the DLC after oil cutoff. (b) XPS analysis of the DLC piston ring in the four stages after oil cutoff. 
(a)
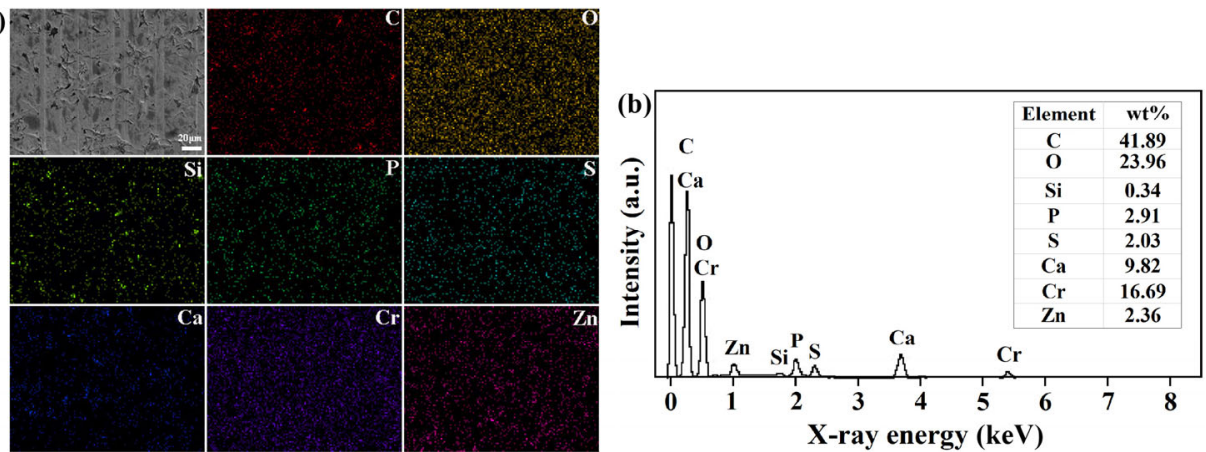

Fig. 13 (a) Element distributions on the worn surface of the D4-stage cylinder liner. (b) EDS spectrum for the marker position shown in Fig. 11(a), D4.

the surface of the piston ring in the four stages after the oil cutoff. The capacity was strong, and no cylinder pulling occurred for $70 \mathrm{~min}$ after the oil cutoff.

The scuffing mechanism of the chrome-plated cylinder liner paired with the GDC and DLC rings was investigated by observing the changes in the $\mathrm{Cr}$ liner subsurface. When the chrome-plated cylinder liner mated with the GDC, the subsurface of the cylinder liner was relatively flat, and there was no peeling debris after $5 \mathrm{~min}$ of oil cutoff (Fig. 14(a), G2). As the reciprocating loading cyclically compressed the sliding interface, surface fatigue may have originated from the microcracks near the subsurface, causing the liner material to peel off, as shown in Fig. 14(a), G3. With the consumption of lubrication oil, direct metal-to-metal contact occurred between the GDC piston ring and the cylinder liner. Thus, the primary wear type changed from surface fatigue to adhesive wear, resulting in severe adhesive wear. With the progress of the adhesive wear, numerous fragments were peeled off and transferred to the ring (Fig. 14(a), G4). When the cylinder liner mated with DLC, the cylinder liner surface was smoother than that in the case of GDC. With the dissipation of the oil film, the fatigue wear was observed. The amount of wear of the cylinder was smaller than that for the GDC pair (Fig. 14(b)). This is because DLC can provide a $C$ tribochemical layer for wear in the scuffing process, slowing the wear of the cylinder liner. This phenomenon agrees with several previous studies [27, 28]. In summary, when the chrome-plated cylinder liner mated with GDC, the scuffing process included fatigue wear transfered to the adhesive, but in the case of DLC, fatigue wear was the only wear mode. Thus, (a)

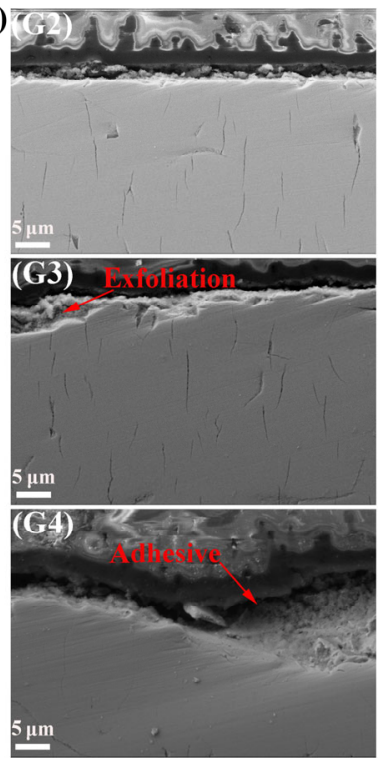

(b)(D2)

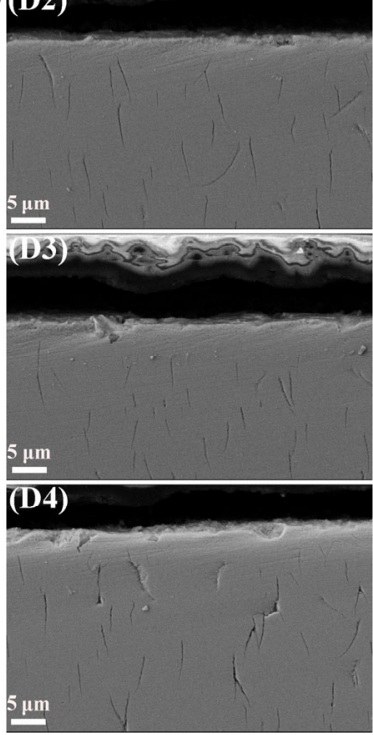

Fig. 14 (a) SEM images of the cross-sectional morphology of the cylinder liner after oil cutoff for the case of GDC. (b) SEM images of the cross-sectional morphology of the cylinder liner after oil cutoff for the case of DLC.

no severe plastic deformation or adhesion of the friction interface was observed.

\section{Conclusions}

The friction and wear performance and scratch resistance of different surface-treated engine piston rings were systematically investigated. The scuffing mechanisms were revealed by interrupted scuffing tests. According to the results, the following conclusions are drawn.

1) The DLC ring exhibited a small coefficient of friction at $150{ }^{\circ} \mathrm{C}$. The nitriding coating yielded the strongest friction force, followed by GDC and 
PVD-CrN. At $240{ }^{\circ} \mathrm{C}$, DLC exhibited the best friction performance at the beginning of the high-loading wear stage, but then scuffing occurred. Thus, GDC exhibited the smallest coefficient of friction in the stable wear stage.

2) The overall wear of the friction pair increased with the temperature. Similar to the friction performance, the amount of wear of the DLC/Cr cylinder liner pair was the smallest at $150{ }^{\circ} \mathrm{C}$. However, at $240{ }^{\circ} \mathrm{C}$, the wear loss of DLC was unmeasurable owing to the scuffing, and the GDC ring exhibited a large wear loss. From the perspective of wear, the PVD CrN/Cr cylinder liner pair is a good candidate at high temperatures.

3) Among the four coatings, the DLC had the best anti-scuffing performance owing to the formation of a mixed oxide and graphitic $\mathrm{C}$ tribolayer. No scuffing occurred for a long time, even without lubrication. The scuffing resistances of the GDC and nitriding coatings were almost identical, and that of PVD-CrN was worse.

4) The friction force of the friction pair decreased suddenly before the cylinder scuffing, possibly owing to the decrease in roughness. Without the lubricant supply, the oil film between the friction pairs was continuously degraded, leading to direct metal contact and eventually scuffing. After the friction force of the DLC decreased suddenly, wear did not occur. This may have been due to the formation of a complex of deposited $C$ and the oil film on the surface, which prevented wear.

5) From the viewpoint of the practical design of the cylinder liner/piston ring pair, in addition to the tribological characteristics under boundary lubrication, the dynamic characteristics and profile of the ring working surface, as well as the elastic force, should be considered. Thus, in the engineering design of the friction pairs, laboratory testing, engine bench testing, and vehicle-level testing should be performed in sequence to make the final choice.

\section{Acknowledgements}

This research was supported by the Natural Science Foundation of Liaoning Province (2019-ZD-0165 and 2020-HYLH-47), the China Postdoctoral Science Foundation (2020M670729), and the National Natural Science Foundation of China (51979018).

Open Access This article is licensed under a Creative Commons Attribution 4.0 International License, which permits use, sharing, adaptation, distribution and reproduction in any medium or format, as long as you give appropriate credit to the original author(s) and the source, provide a link to the Creative Commons licence, and indicate if changes were made.

The images or other third party material in this article are included in the article's Creative Commons licence, unless indicated otherwise in a credit line to the material. If material is not included in the article's Creative Commons licence and your intended use is not permitted by statutory regulation or exceeds the permitted use, you will need to obtain permission directly from the copyright holder.

To view a copy of this licence, visit http://creativecommons.org/licenses/by/4.0/.

\section{References}

[1] Wong V W, Tung S C. Overview of automotive engine friction and reduction trends-Effects of surface, material, and lubricant-additive technologies. Friction 4(1): 1-28 (2016)

[2] Martins R, Amaro R, Seabra J. Influence of low friction coatings on the scuffing load capacity and efficiency of gears. Tribol Int 41(4): 234-243 (2008)

[3] Kamps T J, Walker J C, Wood R J, Lee P M, Plint A G. Reproducing automotive engine scuffing using a lubricated reciprocating contact. Wear 332-333: 1193-1199 (2015)

[4] dos Santos Filho D, Tschiptschin A P, Goldenstein H. Effects of ethanol content on cast iron cylinder wear in a flex-fuel internal combustion engine-A case study. Wear 406-407: 105-117 (2018)

[5] Rao X, Sheng C X, Guo Z W, Yuan C Q. Effects of thread groove width in cylinder liner surface on performances of diesel engine. Wear 426-427: 1296-1303 (2019)

[6] Farfan-Cabrera L I, Gallardo-Hernández E A, PérezGonzález J, Marín-Santibáñez B M, Lewis R. Effects of Jatropha lubricant thermo-oxidation on the tribological behaviour of engine cylinder liners as measured by a reciprocating friction test. Wear 426-427: 910-918 (2019) 
[7] Ajayi O O, Lorenzo-Martin C, Erck R A, Fenske G R. Scuffing mechanism of near-surface material during lubricated severe sliding contact. Wear 271(9-10): 1750-1753 (2011)

[8] Friedrich C, Berg G, Broszeit E, Rick F, Holland J. PVD $\mathrm{Cr}_{x} \mathrm{~N}$ coatings for tribological application on piston rings. Surf Coat Technol 97(1-3): 661-668 (1997)

[9] Erdemir A, Donnet C. Tribology of diamond-like carbon films: Recent progress and future prospects. J Phys D: Appl Phys 39(18): R311-R327 (2006)

[10] Wang J J, Pu J B, Zhang G G, Wang L P. Architecture of superthick diamond-like carbon films with excellent high temperature wear resistance. Tribol Int 81: 129-138 (2015)

[11] Huang R X, Ma S Q, Zhang M D, Xu J J, Wang Z Y. Dynamic deformation and failure process of quasi-closed-cell aluminum foam manufactured by direct foaming technique. Mater Sci Eng: A 756: 302-311 (2019)

[12] Kusmanov S A, Silkin S A, Smirnov A A, Belkin P N. Possibilities of increasing wear resistance of steel surface by plasma electrolytic treatment. Wear 386-387: 239-246 (2017)

[13] Liu K, Kang J J, Zhang G, Lu Z B, Yue W. Effect of temperature and mating pair on tribological properties of DLC and GLC coatings under high pressure lubricated by MoDTC and ZDDP. Friction 9(6): 1390-1405 (2021)

[14] Wan S H, Li D S, Zhang G A, Tieu A K, Zhang B. Comparison of the scuffing behaviour and wear resistance of candidate engineered coatings for automotive piston rings. Tribol Int 106: 10-22 (2017)

[15] Enthoven J, Spikes H A. Infrared and visual study of the mechanisms of scuffing. Tribol Trans 39(2): 441-447 (1996)

[16] Cutiongco E C, Chung Y W. Prediction of scuffing failure based on competitive kinetics of oxide formation and removal: Application to lubricated sliding of AISI 52100 steel on steel. Tribol Trans 37(3): 622-628 (1994)

[17] Hershberger J, Ajayi O O, Zhang J, Yoon H, Fenske G R. Evidence of scuffing initiation by adiabatic shear instability. Wear 258(10): 1471-1478 (2005)

[18] Hershberger J, Ajayi O O, Zhang J, Yoon H, Fenske G R.

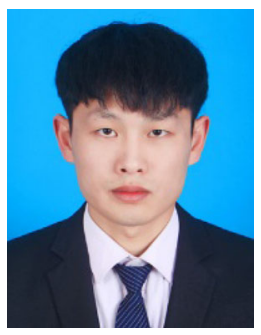

Zeyu MA. He received his B.S. and M.S. degrees from Anhui University of Technology (China, 2017) and Dalian Maritime University (China, 2021), respectively. He is currently
Formation of austenite during scuffing failure of SAE 4340 steel. Wear 256(1-2): 159-167 (2004)

[19] Markov D, Kelly D. Mechanisms of adhesion-initiated catastrophic wear: Pure sliding. Wear 239(2): 189-210 (2000)

[20] Piekoszewski W, Szczerek M, Tuszynski W. The action of lubricants under extreme pressure conditions in a modified four-ball tester. Wear 249(3-4): 188-193 (2001)

[21] Yagi K, Kajita S, Izumi T, Koyamachi J, Tohyama M, Saito K, Sugimura J. Simultaneous synchrotron X-ray diffraction, near-infrared, and visible in situ observation of scuffing process of steel in sliding contact. Tribol Lett 61(2): 19 (2016)

[22] Matsuzaki Y, Yagi K, Sugimura J. In-situ fast and long observation system for friction surfaces during scuffing of steel. Wear 386-387: 165-172 (2017)

[23] Ma S, Liu Y, Wang Z C, Wang Z, Huang R, Xu J. The effect of honing angle and roughness height on the tribological performance of CuNiCr iron liner. Metals 9(5): 487 (2019)

[24] Ma S Q, Chen W B, Li C D, Jin M, Huang R X, Xu J J. Wear properties and scuffing resistance of the $\mathrm{Cr}-\mathrm{Al}_{2} \mathrm{O}_{3}$ coated piston rings: The effect of convexity position on barrel surface. J Tribol 141(2): 021301 (2019)

[25] Abdullah Tasdemir H, Wakayama M, Tokoroyama T, Kousaka H, Umehara N, Mabuchi Y, Higuchi T. The effect of oil temperature and additive concentration on the wear of non-hydrogenated DLC coating. Tribol Int 77: 65-71 (2014)

[26] Qu J, Meyer H M III, Cai Z B, Ma C, Luo H. Characterization of ZDDP and ionic liquid tribofilms on non-metallic coatings providing insights of tribofilm formation mechanisms. Wear 332-333: 1273-1285 (2015)

[27] Tas M O, Banerji A, Lou M, Lukitsch M J, Alpas A T. Roles of mirror-like surface finish and DLC coated piston rings on increasing scuffing resistance of cast iron cylinder liners. Wear 376-377: 1558-1569 (2017)

[28] Bai C N, Gong Z B, An L L, Qiang L, Zhang J Y, Yushkov G, Nikolaev A, Shandrikov M, Zhang B. Adhesion and friction performance of DLC/rubber: The influence of plasma pretreatment. Friction 9(3): 627-641 (2021)

a Ph.D. student at the School of Mechanical Engineering, Xi'an Jiaotong University, China. His current research is tribological properties of the surface modified piston rings under high intensified conditions. 


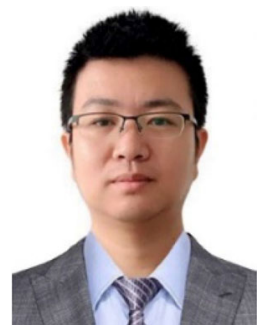

Ruoxuan HUANG. He received his B.S. and Ph.D. degrees from Tianjin University (China, 2007) and Nanyang Technological University (Singapore, 2016), respectively. He is working as an associate professor in the Department of Materials

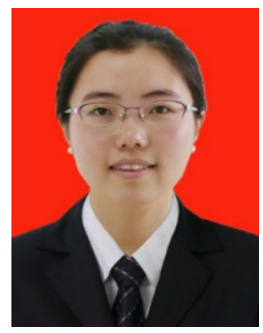

Xiaoshuai YUAN. She received her B.S. and M.S. degrees from Dalian Maritime University in 2010 and 2013, respectively. She is working

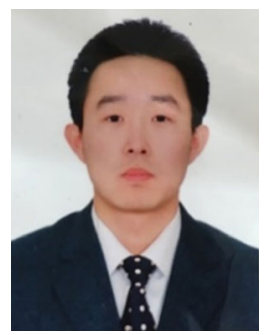

Yan SHEN. He received his B.S. and Ph.D. degrees from Dalian Maritime University in 2003 and 2014, respectively. He is currently an associate professor at Dalian

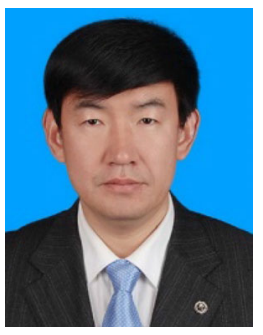

Jiujun XU. He received his B.S. and Ph.D. degrees from Dalian University of Technology (China, 1989) and Dalian Maritime University (China, 1996), respectively. He is working as a professor in the Department of Materials Science and Engineering, Dalian Maritime University. His research interests include the development of tribotest techniques for study tribology processes, especially for the key friction pairs in internal combustion engines. He has been awarded many prizes, including the second prize of
Science and Engineering, Dalian Maritime University. His research interests cover the tribology in internal combustion engine and associated friction-reduction and anti-wear method. He has published 25 peerreviewed papers indexed by SCI and obtained 4 licensed invention patents.

at the China North Engine Research Institute. Her research interest is friction and wear in the piston ring-cylinder liner system.

Maritime University. His research interests cover tribological design of diesel engine components, microtextured surface preparation and performance evaluation, and self-lubricating composites.

the National Science and Technology Progress of China, the first prize of the National Defense Science and Technology Progress of China, and the first prize of the Science and Technology Progress of Liaoning province, etc. He has published over 70 peer-reviewed papers indexed by SCI and obtained more than 15 licensed invention patents. He recently wrote a book entitled Tribology in piston ring-cylinder liner system of diesel engine. It builds a bridge between the essential tribological findings and the engineering design, especially for the diesel engine used piston ring-cylinder liner system. 